\title{
Conditions of preexposure and passive avoidance behavior in rats
}

\author{
ROGER L. MELLGREN and JAMES P. HUNSICKER \\ University of Oklahoma, Norman, Oklahoma 73069
}

and

\author{
DENNIS G. DYCK \\ University of Manitoba, Winnipeg, Manitoba, Canada
}

\begin{abstract}
In the first experiment, rats given a 5-min period of preexposure (simple exploration) to a two-compartment box showed poorer passive avoidance of the compartment where they were subsequently shocked than a control group which was not preexposed to the apparatus. The second experiment involved preexposure to sugared milk (SM), flashing light and loud noise (LN), or simply the apparatus (EC). One group received no exposure to the apparatus (NC). Following one shock trial, the groups were ordered $\mathrm{LN}>\mathrm{NC}>\mathrm{EC}>\mathrm{SM}$ from most to least passive avoidance. The results were discussed in the context of latent inhibition and an averaging model of positive and negative events.
\end{abstract}

Nonreinforced preexposure to a stimulus may result in a decrement in subsequent conditioning to that stimulus (Lubow, 1963). This phenomenon has been called a latent inhibition effect. In particular, it has been shown that preexposure to a discrete CS may result in a decrement in active avoidance (shuttlebox) learning (Ackil \& Mellgren, 1970; Ackil, Mellgren, Halgren, \& Frommer, 1970). The present experiments tested the effects of preexposure on passive avoidance behavior.

\section{EXPERIMENT I}

In the first experiment, rats were preexposed for $5 \mathrm{~min}$ to a two-compartment box and were subsequently given a strong electric shock in one of the compartments. Control (nonpreexposed) rats were treated in the same way except the $5 \mathrm{~min}$ of preexposure was to a completely different environment. All subjects were tested $24 \mathrm{~h}$ later for passive avoidance of the shock compartment. If preexposure exerts a decremental effect on the acquisition of passive avoidance, the experimental group should enter the shock compartment sooner than the control group. In addition, the preexposed (PE) and control (C) groups were divided into subgroups. Half of the subjects received the shock following their entrance into the shock compartment from the safe compartment [a response contingent $(\mathrm{RC})$ shock]. The other half were simply placed $(\mathrm{P})$ into the shock compartment and given the shock. Previous results indicate that a response-contingent shock is more effective in producing passive avoidance than direct placement (Calhoun \& Murphy, 1969; Mellgren, Willison, \& Dickson, 1973), although there is some discrepant data (Blanchard \& Blanchard, 1968). Of interest was the relationship

Reprint requests should be addressed to Roger L. Mellgren, Department of Psychology, University of Oklahoma, Norman, Oklahoma 73069 . between the response-contingent and placed procedures and the preexposure procedures on the acquisition of passive avoidance behavior.

\section{Method}

Subjects. A total of 24 male albino rats approximately 90 days old were used. They were housed individually and allowed free access to food and water throughout the experiment.

Apparatus. A wooden box measuring $90 \mathrm{~cm}$ long, $14 \mathrm{~cm}$ wide, and $30 \mathrm{~cm}$ deep was used. The entire apparatus was painted flat black and was divided into two parts $22 \mathrm{~cm}$ long (safe compartment) and $68 \mathrm{~cm}$ long (shock compartment) by a clear Plexiglas guillotine door. The grid floor consisted of aluminum tubes $13 \mathrm{~mm}$ in diam, spaced $4 \mathrm{~cm}$ center-to-center. The entire apparatus was covered by a hinged hardware cloth top. A Grason-Stadler shocker (Model 700) was used to deliver a scrambled shock of $1.0 \mathrm{~mA}$.

Procedure. The design of the experiment was a 2 by 2 factorial. One half of the subjects were given $5 \mathrm{~min}$ of preexposure to the apparatus ("exploration" with the guillotine door up), while the other half of the subjects were placed in a covered wastepaper basket (solid metal, light brown in color) for the same period. One minute after these treatments, the subjects received one trial of passive avoidance training. For half the subjects in each preexposure condition, the passive avoidance trial consisted of being placed in the safe compartment with the guillotine door down. After $5 \mathrm{sec}$, the guillotine door was raised, and when the subject entered the shock compartment (defined as the back paw reaching the third bar in the shock area) the door was lowered and the subject received a $5-\sec 1.0-\mathrm{mA}$ shock and was then removed from the apparatus. The other half of the subjects in each preexposure condition were placed directly in to the shock compartment with the guillotine door down and after $5 \mathrm{sec}$ received a $1.0-\mathrm{mA}$ shock for $5 \mathrm{sec}$ and were then removed. Before each subject was placed in the apparatus, fresh paper was placed below the grid floor and the floor and sides were washed with sponge and water. Thus, the 2 by 2 factorial design involves preexposure to the apparatus (PE) and preexposure to a distinctively different environment $(\mathrm{C})$, and $d$ responsecontingent shock (RC) and a shock following direct placement in the shock compartment $(P)$. This defines four groups-PE-RC, PE-P, C-RC, and C-P.

Testing for the acquisition of passive avoidance was carried out $254 \mathrm{~h}$ and $48 \mathrm{~h}$ following the single acquisition trial. During 
Table 1

Measures of Passive Avoidance for Experiment I

\begin{tabular}{lrrrr} 
& \multicolumn{4}{c}{ Experimental Condition } \\
\cline { 2 - 5 } $\begin{array}{l}\text { Measures of } \\
\text { Passive Avoidance }\end{array}$ & PE-RC & \multicolumn{1}{c}{ C-RC } & \multicolumn{1}{c}{ PE-P } & C-P \\
\hline Initial Exit & & & \\
Latency (min) & .76 & 23.10 & 1.73 & 13.82 \\
Number of Exits & 18.00 & 5.33 & 17.17 & 11.17 \\
Time in Shock & 13.78 & 2.07 & 11.40 & 5.45 \\
Compartment (min) & & & & \\
\hline
\end{tabular}

each of the 15-min tests, the subject was placed in the safe compartment, and 5 sec later the guillotine door was raised. The three measures of passive avoidance were: (1) Initial exit latency [the time between the opening of the guillotine door and the subject reaching a point where its backpaws were on the third bar in the shock compartment (IEL)]; (2) Time in shock compartment [the total amount of time the subject was in the shock compartment (time in SC)] ; and (3) Number of crosses [the number of times the subject crossed between the safe and shock compartments (crosses)]. No shock was delivered on the test trials.

\section{Results}

Since all measures were significant or nonsignificant in the same manner, only the analysis of the initial exit latency will be presented, although the means for all measures are shown in Table 1 . The main effect for $P E$ vs. $C$ was significant $[F(1,20)=47.73 ; p<.001]$. From Table 1 , it is clear that this main effect is produced by better passive avoidance for the $\mathrm{C}$ groups as compared to the PE groups. The RC vs. $\mathrm{P}$ shock was a nonsignificant source of variance $[F(1,20)=2.77 ; p>.05]$, although there was a tendency for the RC groups to show superior passive avoidance. The interaction of the kind of preexposure and response-contingent placed shock was marginally significant for the initial exit latency measure $[F(1,20)=4.23 ; p<.06]$ but not for other measures. This interaction was produced by the differences between the C-RC and C-P groups as shown by the significant difference between these two groups $[\mathrm{t}(10)=2.63 ; \mathrm{p}<.05]$. In summary, the results of this experiment show a decrement in passive avoidance behavior as a function of prior nonreinforced exposure to the safe and shock compartments of the passive avoidance apparatus, and a relatively small (and generally nonsignificant) effect of response-contingent shock.

\section{Discussion}

The results of this experiment have two major implications. First, a latent inhibition effect is demonstrated for passive avoidance. Since preexposure to a CS for active avoidance results in a decrement in the acquisition of that response (Ackil \& Mellgren, 1970; Ackil et al., 1970), and in the present experiment, a decrement in the acquisition of a passive avoidance response was found as a function of preexposure, it is implied that a response-competition explanation of latent inhibition (Lubow, 1973) is inadequate since the active and passive avoidance situation involve incompatible responses (running vs. not running).

A second implication is tied more closely to passive avoidance. Church (1969) has suggested an "incomplete shift," or inertia hypothesis to account for the effects of preexposure to shock. If a rat were given a strong shock prior to a weak shock in a passive avoidance situation, then the subject would react more strongly to the weak passive avoidance shock. Similarly if the rat has had prior exposure to a weak shock, subsequent passive avoidance to a strong shock will be attenuated. Thus, prior shocks are averaged with subsequent shocks. If the preexposure to the apparatus in the present experiment is labeled "preextinction," or prior experience with a zero shock level, then these results are consistent with the inertia hypothesis. Prior experience with no shock results in an attenuation of the effect of a subsequent strong shock in passive avoidance. Experiment II is an attempt to test and extend this hypothesis.

\section{EXPERIMENT II}

We may rephrase the inertia hypothesis in a more general framework: Prior experience with stimuli in a punishment situation will result in an averaging of the value of these stimuli with the subsequent punishing stimulus. This average will then determine the degree of passive avoidance. Raymond (1968) has shown that prior exposure to a weak shock will attenuate the degree of response suppression produced by a subsequent strong shock. Conversely, prior experience with strong shock will augment the suppressive effects of a subsequent weak shock. According to the inertia hypothesis, these results are understandable because the average of the prior and subsequent shocks would be intermediate to the subject receiving only the second shock level. A "generalized inertia hypothesis" has a much stronger implication. According to this hypothesis, not only prior exposure to shock, but prior exposure to any stimulus will result in passive avoidance behavior which is governed by an average of the relative positive or negative value of the prior stimulus and the negative value of the stimulus used to produce passive avoidance. This hypothesis was tested by giving different subjects experience with a positive-value stimulus (milk and sugar added), a presumably zero-value stimulus (exploration or preexposure as in Experiment I), a negative-value stimulus (a bright flashing light and intermittent strong noise), prior to one-trial passive avoidance conditioning using shock as the punishing stimulus. In addition, a control group received no prior experience in the passive avoidance apparatus, serving as a baseline from which to assess the effects of the various preexposure conditions. Averaging the positive-, zero-, negative-, and noexperience procedures with the negatively valued shock received on the training trial leads to the 
prediction that the groups should order negative $>$ control $>$ zero $>$ positive from most to least passive avoidance performance.

\section{Method \\ Subjects. A total of 32 rats like those in Experiment I were used.}

Apparatus. The passive avoidance apparatus was the same as that described in Experiment 1 except that one compartment was painted black and the other was painted white. In addition, a General Electric 150-W floodlight and a 12.5 -cm-diam speaker connected to a white-noise generator were used.

Procedure. A pilot study was conducted on two subjects not included in the actual design to ensure that the light and noise stimuli were aversive (i.e., the subjects learned to escape from the light and noise compound).

The subjects were then randomly assigned to one of four preexposure conditions. Preexposure lasted $5 \mathrm{~min}$ and preceded the passive avoidance trial by $6 \mathrm{~min}$. Group SM (sugared milk) had milk with sugar added available through a drinking tube in the black compartment for $5 \mathrm{~min}$. Group LN (light noise) received $2 \mathrm{sec}$ of noxious $150-\mathrm{W}$ light and $100-\mathrm{dB}$ noise every $4 \mathrm{sec}$ throughout the 5-min preexposure treatment; Group EC (exposure control) was just preexposed to the black compartment ("exploration") for $5 \mathrm{~min}$; and Group NC (no-treatment control) had no prior contact with the apparatus but was handled the same as the other groups, and placed in covered wastepaper basket for $5 \mathrm{~min}$.

Acquisition of passive avoidance involved the placed (P) procedure described in Experiment 1.

Two 15 -min tests, 24 and $48 \mathrm{~h}$ after acquisition, were made. In addition to the three dependent variables measured in Experiment I, time spent crouching $(\mathrm{C})$, an index of generalized fear (Blanchard \& Blanchard, 1969) was recorded. The derived measure, initial exit latency minus time spent crouching, (IEL-C) was also obtained.

Due to a malfunction in the shock source, one subject in both the SM and EC treatment groups had to be discarded. One subject in Group LN pushed its way out of the black compartment during testing and was also dropped. In order to keep the groups equal in size, one randomiy chosen subject from Group NC was discarded, leaving seven subjects in each treatment.

\section{Results}

The means of the five measures of passive avoidance over the four treatments are shown in Table 2. For each measure, the groups rank in the same order: $\mathrm{LN}, \mathrm{NC}, \mathrm{EC}$, and SM from greatest to least passive avoidance.

A one-way ANOVA was used to analyze each of the five measures on each day of testing. The analyses showed that IEL, $\mathrm{C}$, and time in SC all yielded significant differences between treatments $(F=9.10$, $\mathrm{F}=13.79$, and $\mathrm{F}=13.73$, respectively, all with $\mathrm{df}=3 / 24$ and $\mathrm{ps}<.01$ ). Number of crosses was also significant $F(3,24)=6.44, p<.05$, but IEL-C differences were not significant, $F(3,24)=2.35$.

A number of post-hoc comparisons were carried out where the overall analysis indicated a significant effect for groups. The differences discussed below were all reliable at the .05 level or better using Tukey's correction procedure. Group SM froze less than Groups NC and LN, and Group EC also froze less than
Table 2

Measures of Passive Avoidance for Experiment II

\begin{tabular}{lrrrr}
\hline & \multicolumn{5}{c}{ Experimental Condition } \\
\cline { 2 - 5 } $\begin{array}{l}\text { Measures of } \\
\text { Passive Avoidance }\end{array}$ & $\mathrm{SM}$ & $\mathrm{EC}$ & $\mathrm{NC}$ & $\mathrm{LN}$ \\
\hline Initial Exit Latency* & 2.00 & 3.54 & 6.59 & 9.24 \\
Time Crouching* & .84 & 1.33 & 5.53 & 9.76 \\
Number of Exits & 21.43 & 18.00 & 11.86 & 8.00 \\
Time in Shock & 14.75 & 9.30 & 6.73 & 3.00 \\
$\quad \begin{array}{l}\text { Compartment* } \\
\text { Initial Exit Latency/ }\end{array}$ & 1.86 & 2.66 & 4.27 & 3.68 \\
\hline Time Crouching* & & & & \\
\hline
\end{tabular}

*Minutes

Group LN. The same pattern of differences was also evident for the number-of-crosses measure. Group SM spent more time in the shock compartment than any of the other groups, and Group EC also spent more time in the shock compartment than Group LN. The only differences on the IEL measure were that Group SM entered the shock compartment faster than Groups NC and $\mathrm{LN}$.

\section{Discussion}

The differences between groups are predicted by the generalized inertia hypothesis. This hypothesis predicts that prior experience with a positive event (e.g., Group SM) will make a subsequent aversive event less noxious and prior experience with a negative event (e.g., Group LN) will make a subsequent aversive event more noxious. Thus, the hypothesis specifically indicates that the prior event interacts with the shock received on the passive avoidance acquisition trial, and modifies the effectiveness of the passive avoidance learning trial. Alternative explanations are possible, however. For example, it could be hypothesized that the learning that occurs on the shock trial is the same for all the groups, but superimposed on this are differential exploratory tendencies. That is, Group SM might be more active and explore the apparatus more vigorously than Group LN because these subjects had previously received an attractive stimulus (sugared milk) in the apparatus. Similarly, subjects which previously had been allowed to explore the apparatus (Group EC) might be more likely to engage in further exploration at the time of the test relative to a group that had not previously been allowed to explore (Group NC). Of course, it is a relatively simple matter to test whether such differences in exploration can account for the data by omitting the passive avoidance acquisition training.

\section{EXPERIMENT III}

This is a control experiment to evaluate the possibility that differences between the groups in Experiment II were due to differing exploratory tendencies as a function of the preexposure condition. Four groups were used which received exactly the same preexposure 
conditions as in Experiment II. The passive avoidance acquisition trial was also the same except the shocker was disconnected. If an explanation based on differing exploratory tendencies is to be viable, then the groups should be ordered in the same manner as comparable groups from Experiment II.

\section{Method}

Subjects. A total of 28 rats like those in Experiment I were used.

Apparatus. The apparatus was the same as that used in Experiment II.

Procedure. The procedure was identical to the one used in Experiment II with the following exceptions: (a) no shock was delivered on the passive avoidance acquisition trial, and (b) only the first test ( $24 \mathrm{~h}$ later) was given, and it lasted for $5 \mathrm{~min}$ rather than $15 \mathrm{~min}$.

\section{Results}

The result of omitting the shock on the training trial was that no rat froze for any measurable period of time on the test trial, and there were no significant differences on the IEL measure between groups $[\mathrm{F}(3,24)=.15]$. The mean IEL times were 5.7,6.3,6.4, and $5.9 \mathrm{sec}$ for SM, EC, NC, and LN groups. Similarly, the $\mathrm{F}$ ratios for the time in the shock compartment and number of crosses dependent variables were less than 1.0. The mean of all subjects' time in SC was 3.1 min of a possible 5 , and the grand mean of the number of crosses was 11.9 , or about one cross per $25 \mathrm{sec}$. The fact that the first cross occurred within $7 \mathrm{sec}$ of the opening of the guillotine door (IELs were all less than $7 \mathrm{sec}$ ) is probably explainable by the fact that the opening of the door would tend to orient the subject toward the door, thereby increasing the probability of a cross into the other compartment.

\section{Discussion}

Experiment III shows that differences between groups in Experiment I and Experiment II cannot be accounted for simply on the basis that the various preexposure conditions were independently accounting for between-group differences, due to alterations in general exploratory tendencies or similar processes. Rather it would seem that the effect of different preexposure conditions was to interact with the passive avoidance acquisition trial, thereby producing differential test performance. The lack of difference between groups in the present experiment thus supports the generalized inertia hypothesis.

\section{GENERAL DISCUSSION}

Consistent with a large body of literature (Lubow, 1973), these experiments indicate that nonreinforced preexposure to the apparatus retards the acquisition of passive avoidance. The decremental effect of nonreinforced preexposure has been attributed to the subject not attending to the preexposed stimuli, but it is questionable whether this explanation can be applied to the present data. In Experiment II, one group of subjects was given preexposure to the apparatus with sugar milk present, and another group was given similar preexposure with a light noise present. It would seem that the SM and LN groups would: (a) be similar to Group EC, or (b) both be superior to Group EC in acquisition of passive avoidance, if only attentional processes were operating.

The first possibility relates to the fact that both Groups SM and LN received an equal amount of preexposure to the apparatus as Group EC. Clearly if just preexposure (without regard to what happens during preexposure) is effective then the three groups should be similar. Since they are obviously different, this hypothesis can be rejected.

The second possibility arises because both Groups SM and $\mathrm{LN}$ experienced the apparatus cues associated with the shock compartment and an important stimulus event (sugar milk or light noise). It might be postulated that the association of the apparatus cues with the attractive or aversive stimulus would increase the saliency of those cues. The increased saliency of the cues associated with the shock compartment would then be expected to produce superior passive avoidance acquisition. Since this is not the case, something other than an attentional variable is implicated (which is not to say that attentional variables are not important in this kind of situation).

The most parsimonious explanation would seem to be the "generalized inertia hypothesis" developed earlier. The averaging of positive and negative stimuli encountered in preexposure with the shock received in passive avoidance training predicts that the groups should order SM, EC, NC, and LN from least to most passive avoidance as was found. It would also appear that the generalized inertia hypothesis might be applied to other situations involving acquisition of appetitively re inforced responses. Indeed, this hypothesis is conceptually similar to previous theoretical statements involving an algebraic interaction of positive and negative incentives (e.g., Logan, 1969; Millenson \& deVilliers, 1972). Furthermore, the relationship between the present kinds of effects where prior experience with stimulus events tends to diminish the effects of subsequent stimuli and situations where prior experience has a facilitating effect on the behavior controlling power of subsequent stimuli (e.g., contrast effects) needs to be considered by general behavioral theories.

\section{REFERENCES}

Ackil, J. E., \& Mellgren, R. L. Stimulus preexposure and instrumental learning. Psy chonomic Science, 1968, 11, 339. Ackil, J. E., Mellgren, R. L., Halgren, C., \& Frommer, G. P. Effects of CS preexposure on avoidance learning in rats with hippocampal lesions. Joumal of Comparative and Physiological Psy chology, 1969, 69, 739-747. 
Blanchard, R. J., \& Blanchard, D. C. Crouching as an index of fear. Journal of comparative and Physiological Psychology $1969,67,370-375$.

Calhoun, W. H., \& Murphy, R. J. Active and passive avoidance conditioning: A direct comparison. Psychonomic Science, $1969,17,176-177$.

Church, R. M. Response suppression. In B. A. Campbell and R. M. Church (Eds.),

Punishment and aversive behavior. New York: Appleton-Century-Crofts, 1969.

Logan, F. A. The negative incentive value of punishment. In B. A. Campbell and R. M. Church (Eds.) Punishment and aversive behavior. New York: Appleton-Century-Crofts, 1969

Lubow, R. E. Latent inhibition. Psychological Bulletin, 1973. 29, 398-407.
Melleren, R. L., Willison, P. W., \& Dickson, A. L. Acquitition of pasaive avoidance in rate. Bulletin of The Paychonomic Society, 1973, 2, 37-38.

Millenson, J. R., \& deVilliers, P. A. Motivational properties of conditioned suppression. Leaming and Motivation, 1972, 3 , 125-137.

Raymond, G. A. Accentuation and attenuation of punishment by prior exposure to aversive stimulation. Dissertation Abstracts International, 1969, 30, 416-417.

(Received for publication September 20, 1974; revision received December 16, 1974.) 